\title{
RELAP-7 Development Updates
}

\author{
Hongbin Zhang \\ Haihua Zhao \\ Frederick Gleicher \\ Mark DeHart \\ Ling Zou \\ David Andrs \\ Richard Martineau
}

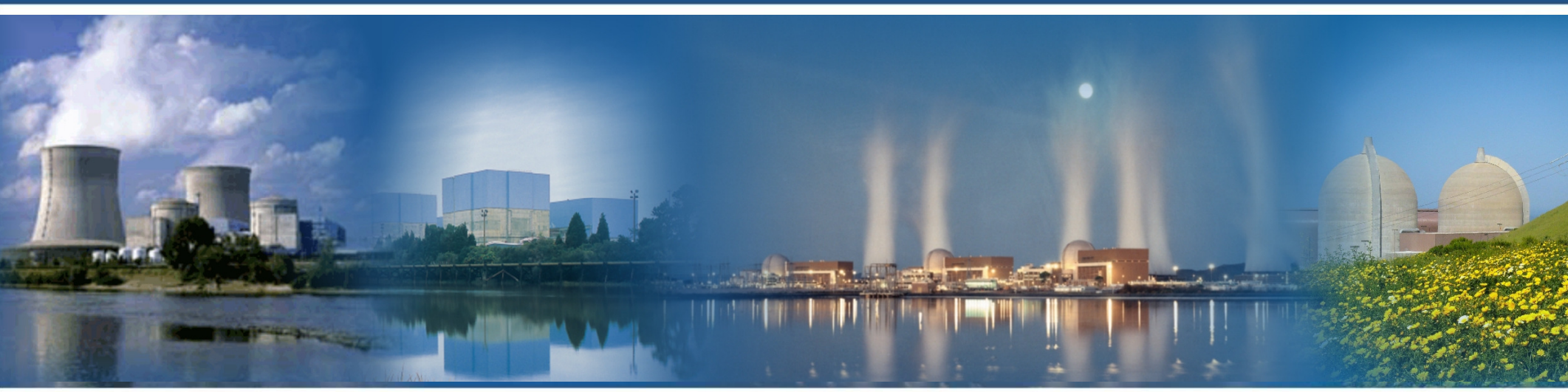

\section{September 2015}




\section{DISCLAIMER}

This information was prepared as an account of work sponsored by an agency of the U.S. Government. Neither the U.S. Government nor any agency thereof, nor any of their employees, makes any warranty, expressed or implied, or assumes any legal liability or responsibility for the accuracy, completeness, or usefulness, of any information, apparatus, product, or process disclosed, or represents that its use would not infringe privately owned rights. References herein to any specific commercial product, process, or service by trade name, trade mark, manufacturer, or otherwise, does not necessarily constitute or imply its endorsement, recommendation, or favoring by the U.S. Government or any agency thereof. The views and opinions of authors expressed herein do not necessarily state or reflect those of the U.S. Government or any agency thereof. 


\title{
RELAP-7 Development Updates
}

Hongbin Zhang, Haihua Zhao, Frederick Gleicher, Mark DeHart, Ling Zou, David Andrs, Richard Martineau

September 2015

\section{Idaho National Laboratory Idaho Falls, Idaho 83415}

http://www.inl.gov

\author{
Prepared for the \\ U.S. Department of Energy \\ Office of Nuclear Energy \\ Under DOE Idaho Operations Office \\ Contract DE-AC07-05ID14517
}





\section{EXECUTIVE SUMMARY}

RELAP-7 is a nuclear systems safety analysis code being developed at the Idaho National Laboratory (INL) and is the next generation tool in the RELAP reactor safety/systems analysis application series. RELAP-7 development began in 2011 to support the Risk Informed Safety Margins Characterization (RISMC) Pathway of the Light Water Reactor Sustainability (LWRS) program. The overall design goal of RELAP-7 is to take advantage of the previous thirty years of advancements in computer architecture, software design, numerical methods, and physical models in order to provide capabilities needed for the RISMC methodology and to support nuclear power safety analysis. The code is being developed based on Idaho National Laboratory's modern scientific software development framework - MOOSE (the Multi-Physics Object-Oriented Simulation Environment). The initial development goal of the RELAP-7 approach focused primarily on the development of an implicit algorithm capable of strong (nonlinear) coupling of the dependent hydrodynamic variables contained in the 1D/2-D flow models with the various 0-D system reactor components that compose various boiling water reactor (BWR) and pressurized water reactor nuclear power plants (NPPs). The first lines of RELAP-7 code were committed to the software revision control repository on November 7th, 2011 and the code development efforts have continued thereafter.

During Fiscal Year (FY) 2015, the RELAP-7 code has been further improved with expanded capability to support boiling water reactor (BWR) and pressurized water reactor nuclear power plants (NPPs) analysis. The accumulator model has been developed. The code has also been coupled with other MOOSE based applications such as neutronics code RattleSnake and fuel performance code BISON to perform multiphysics analysis.

A major design requirement for the implicit algorithm in RELAP-7 is that it is capable of second-order discretization accuracy in both space and time, which eliminates the traditional first-order approximation errors. The second order temporal is achieved by a second-order backward temporal difference and the one-dimensional second-order accurate spatial discretization is achieved with the Galerkin approximation of Lagrange finite elements. During FY-2015, we have done numerical verification work to verify that the RELAP-7 code indeed achieves 2nd-order accuracy in both time and space for single phase models at the system level. 


\section{ACKNOWLEDGEMENTS}

We would like to acknowledge Stephen Hess and Greg Swindlehurst of the Electric Power Research Institute for their valuable contributions to development of the RELAP-7 applications. Their expertise in nuclear engineering, systems analysis and understanding of industry needs is much appreciated. We also acknowledge contributions of the MOOSE team. 


\section{CONTENTS}

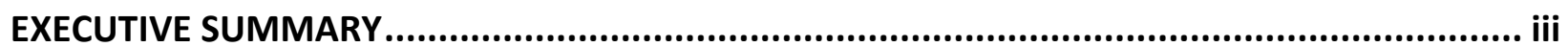

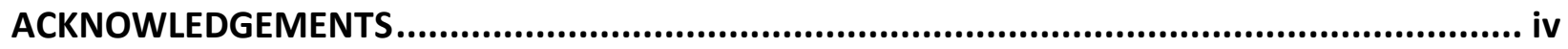

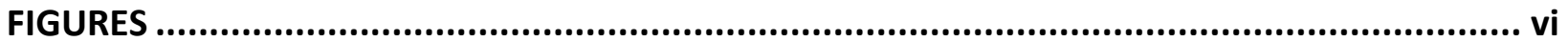

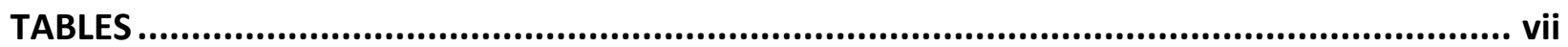

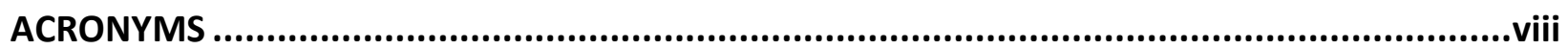

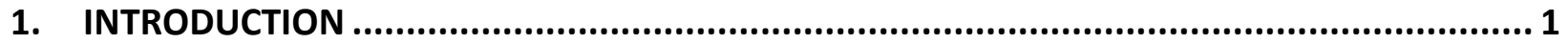

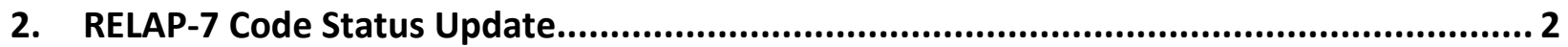

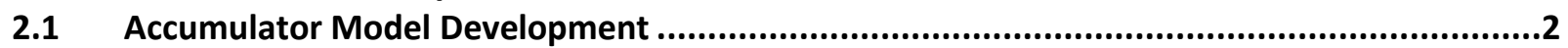

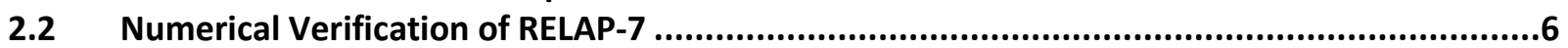

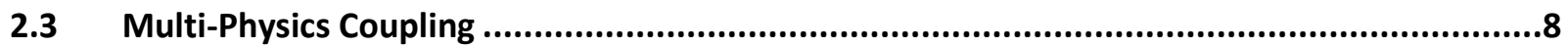

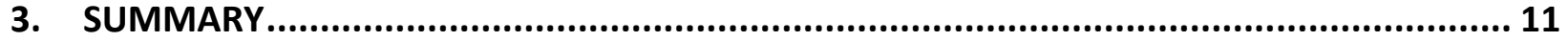

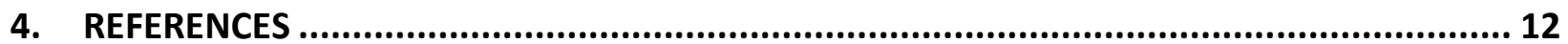




\section{FIGURES}

Figure 1. Typical Cylindrical Accumulator [5] ......................................................................... 2

Figure 2. AP1000 system safety system (Credit of Westinghouse) …................................................. 3

Figure 3. LOFT L3-1 accumulator and surge line schematic [10] .................................................... 4

Figure 4. Calculated RELAP-7 accumulator gas pressure versus LOFT L3-1 experimental data. .............. 5

Figure 5. Calculated RELAP-7 accumulator water level versus LOFT L3-1 experimental data. ............... 5

Figure 6. Schematic of the natural circulation loop problem......................................................... 7

Figure 7. Spatial convergence rate for mass flow rate error. ............................................................. 7

Figure 8. Plot of fuel rod radial average temperature $[\mathrm{K}]$ before station blackout (left figure) and plot of fuel power density [Watts/cu m] before station blackout (right figure). ......................................... 10

Figure 9. Plot of liquid-vapor fraction vs. fuel rod height both before station blackout (SBO) and 68.45

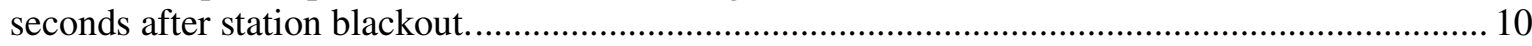




\section{TABLES}

Table 1. Dimensions of single Westinghouse 17x17 Fuel Pin ............................................................ .9 


\section{ACRONYMS}

0-D zero-dimensional

1-D one-dimensional

2-D two-dimensional

BWR boiling water reactor

ECCS emergency core cooling system

FY fiscal year

HX heat exchanger

IET integral effect test

INL Idaho National Laboratory

LOFT loss-of-fluid test

LWRS Light Water Reactor Sustainability

MOOSE Multi-Physics Object-Oriented Simulation Environment

NPP nuclear power plant

PCT peak clad temperature

RELAP5 Reactor Excursion and Leak Analysis Program 5

RELAP-7 Reactor Excursion and Leak Analysis Program 7

RISMC risk informed safety margin characterization

SBO station blackout

SET separate effect test 


\section{INTRODUCTION}

RELAP-7 is a nuclear systems safety analysis code being developed at the Idaho National Laboratory (INL) [1-4] and is the new generation tool in the RELAP reactor safety/systems analysis application series. RELAP-7 development began in 2011 to support the Risk Informed Safety Margins Characterization (RISMC) Pathway of the Light Water Reactor Sustainability (LWRS) program. The overall design goal of RELAP-7 is to take advantage of the previous thirty years of advancements in computer architecture, software design, numerical methods, and physical models in order to provide capabilities needed for the RISMC methodology and to support nuclear power safety analysis. The code is being developed based on Idaho National Laboratory's modern scientific software development framework - MOOSE (the Multi-Physics Object-Oriented Simulation Environment). The first lines of RELAP-7 code were committed to the software revision control repository on November 7th, 2011 and the code development efforts have continued thereafter.

During Fiscal Year (FY) 2015, the RELAP-7 code has been further improved with expanded capability to support boiling water reactor (BWR) and pressurized water reactor nuclear power plants (NPPs) analysis. The accumulator model has been developed. The code has also been coupled with other MOOSE based applications such as neutronics code RattleSnake and fuel performance code BISON to perform multi-physics analysis.

The initial algorithmic development goal of the RELAP-7 approach focused primarily on the development of an implicit algorithm that is capable of strong (nonlinear) coupling of the dependent hydrodynamic variables contained in the 1-D/2-D flow models with the various 0 -D system reactor components for PWRs and BWRs. A major design requirement for this implicit algorithm is that it is capable of second-order discretization accuracy in both space and time, which eliminates the traditional first-order approximation errors. The second order temporal is achieved by a second-order backward temporal difference and the one-dimensional second-order accurate spatial discretization is achieved with the Galerkin approximation of Lagrange finite elements. During FY-2015, we have done numerical verification work to verify that the RELAP-7 code indeed can achieve second order accuracy in both time and space for single phase models at the system level. 


\section{RELAP-7 Code Status Update}

This section provides a status update on the components development, numerical verification for the RELAP-7 code, as well as multi-physics coupling.

\subsection{Accumulator Model Development}

Accumulators are designed to passively provide water to the PWR reactor core during emergencies in which the pressure drops rapidly, such as large primary breaks. Accumulator is the only passive component within Emergency Core Cooling Systems (ECCS) which provides core cooling to minimize fuel damage following a loss of coolant. The accumulators do not require electrical power to operate. These tanks contain large amounts of borated water with a pressurized nitrogen gas in the top. Figure 1 shows one cylindrical accumulator model used for RELAP5 [5]. If the pressure of the primary system drops below the setting point, the nitrogen will force the borated water out of the tank and into the reactor coolant system. There are two types of tank shapes: cylinder or sphere. As an example, the advanced PWR AP1000 design developed by Westinghouse uses spherical accumulators as shown in Figure 2.

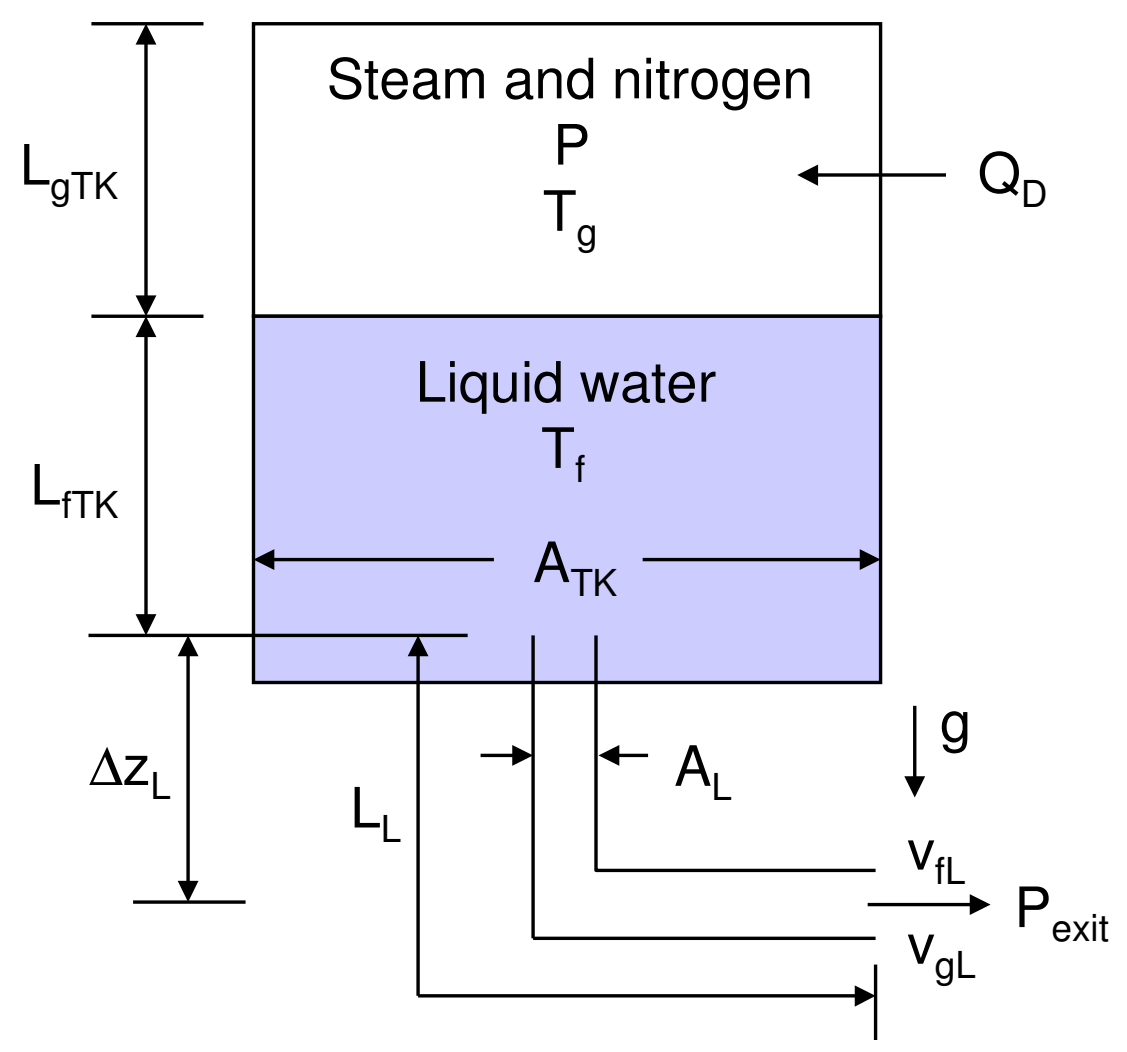

Figure 1. Typical Cylindrical Accumulator [5]

A new accumulator component has been successfully developed in RELAP-7. It is based on the modified RELAP-5 accumulator model $[5,6]$. In the RELAP-5 model, the following assumptions are used:

- $\quad$ Using a lumped parameter model (0-D) since spatial gradients are small.

- Natural convection heat transfer correlations are used for tank walls and liquid surface.

- Mass transfer is based on similarity between heat and mass transfer. 
- The gas in the dome is modeled as a closed expanding system composed of an ideal gas with constant specific heat and steam at a low partial pressure.

- Energy transport from the liquid surface to the gas dome is from the vaporization/condensation process.

- The water is modeled as an isothermal system which had been validated by experimental data [7].

- The model for liquid flow includes inertia, wall friction, form loss, and gravity.

- The geometry of the tank may be cylindrical or spherical.

- The accumulator model also includes the surge line and an outlet check valve junction.

The major assumptions from RELAP5 are kept in the RELAP-7 accumulator model, except for the following treatments:

- The RELAP-7 Accumulator component does not include the surge line and check valve models which are simulated as Pipe and CheckValve Components, respectively.

- The momentum equation only accounts for the water flow from the water free surface to the surge line inlet; the integrated momentum equation becomes much easier to follow and modify (i.e., for future advanced accumulator model [8]) than in the RELAP5 model.

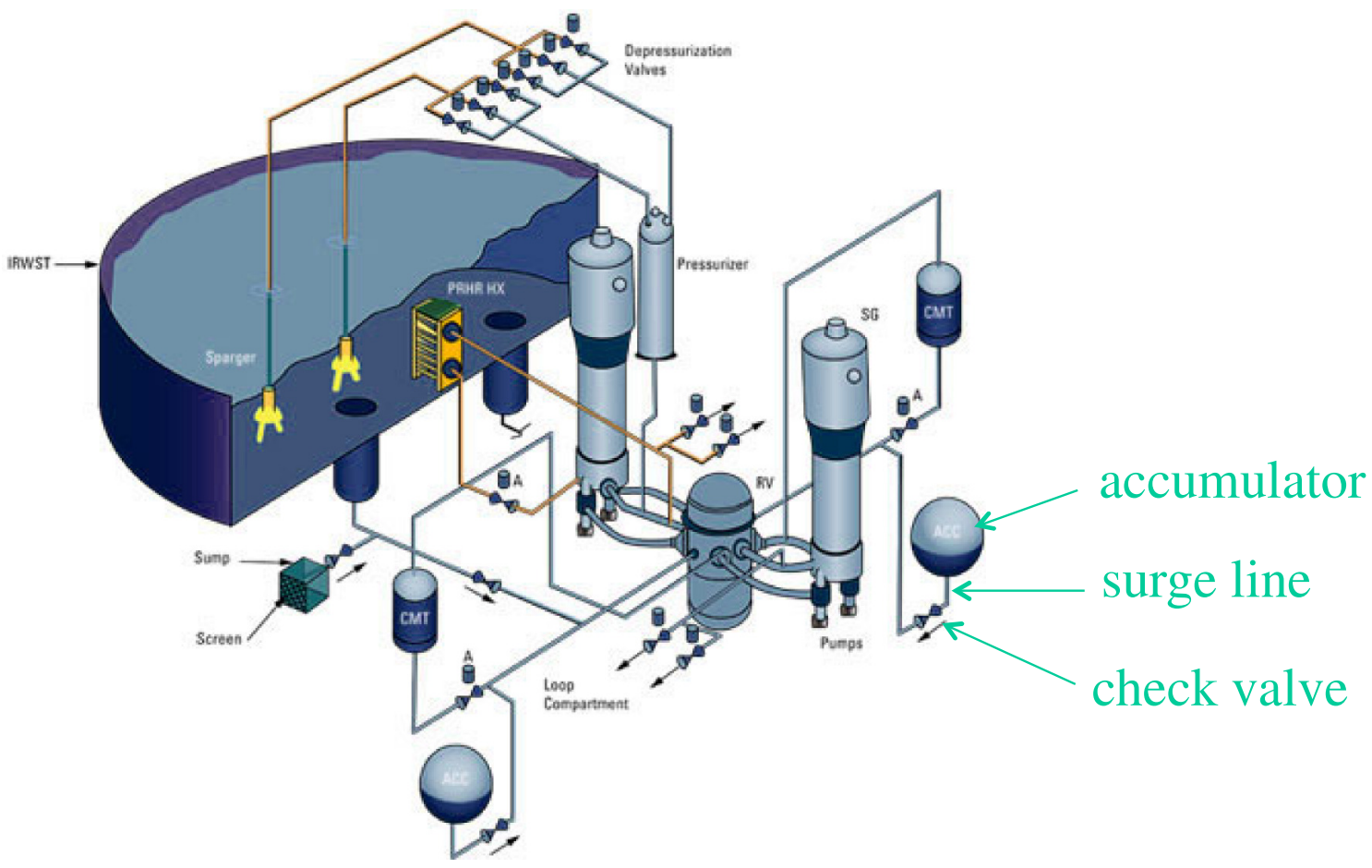

Figure 2. AP1000 system safety system (Credit of Westinghouse).

Even with similar physical models, the implementation of the accumulator model in RELAP-7 is quite different from RELAP5. In RELAP5 or other traditional system analysis codes, physical models and numerical methods are strongly coupled together. Model specific numerical derivations are required to fit in the semi-implicit time integration method. Once finished, it is difficult to modify, i.e., updating from the semi-implicit method to a fully implicit method or updating the models to account for advanced design features [8]. Thanks to the advanced software design and numerical methods adopted in RELAP-7 (inheriting from the MOOSE framework), physical models and numerical methods can be fully decoupled in RELAP-7. As a result, the code is much easier to implement, read, and modify, comparing to 
traditional methods. No model specific numerical derivations are required. Users can choose different time integration methods provided through MOOSE, such as $1^{\text {st }}$ order fully implicit Backward-Euler method or $2^{\text {nd }}$ order fully implicit BDF2 method.

The modified accumulator model contains 30 equations [9]. Nine equations are chosen for the primary variables. The other majority of equations are for special physical processes and geometry relationships. In order to effectively manage these special models and their Jacobians (the derivative of a residual equation with any primary variable), a new 0-D component design pattern was developed. In this new component design method, all the special models and their Jacobians are handled through a MOOSE UserObject. This method proved to be able of easily managing large amount of special models and their Jacobians, and helping avoid coding errors.

The accumulator component is the first production quality 0-D component model in the RELAP-7 code. The accumulator model can be validated against experimental data and therefore can be used for safety analysis work. The model has been validated with Loss-of-Fluid Test (LOFT) experimental data [7, 10]. LOFT Experimental L3-1 is a small break loss-of-coolant accident integral effect test (IET). The related experimental data were extracted from L3-1 to generate a separate effect test (SET) for the accumulator model in RELAP5 [10]. The purpose of this problem was to assess the performance of the accumulator model during a slow depressurization associated with a small break loss-of-coolant accident. Figure 3 shows the schematic of the LOFT L3-1 accumulator and surge line. Experimental data including accumulator gas space pressure and water level are compared to RELAP-7 simulation results in Figure 4 and 5. Excellent agreement between simulation and experimental data can be seen in the figures.

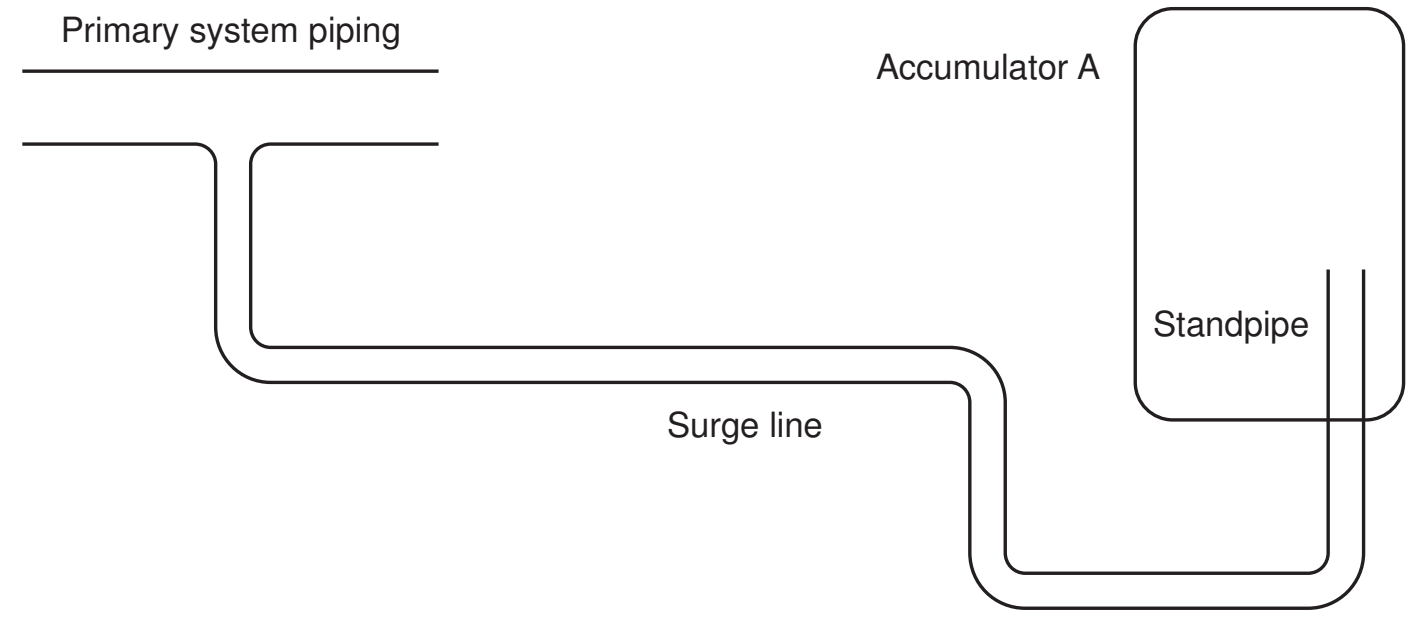

Figure 3. LOFT L3-1 accumulator and surge line schematic [10] 


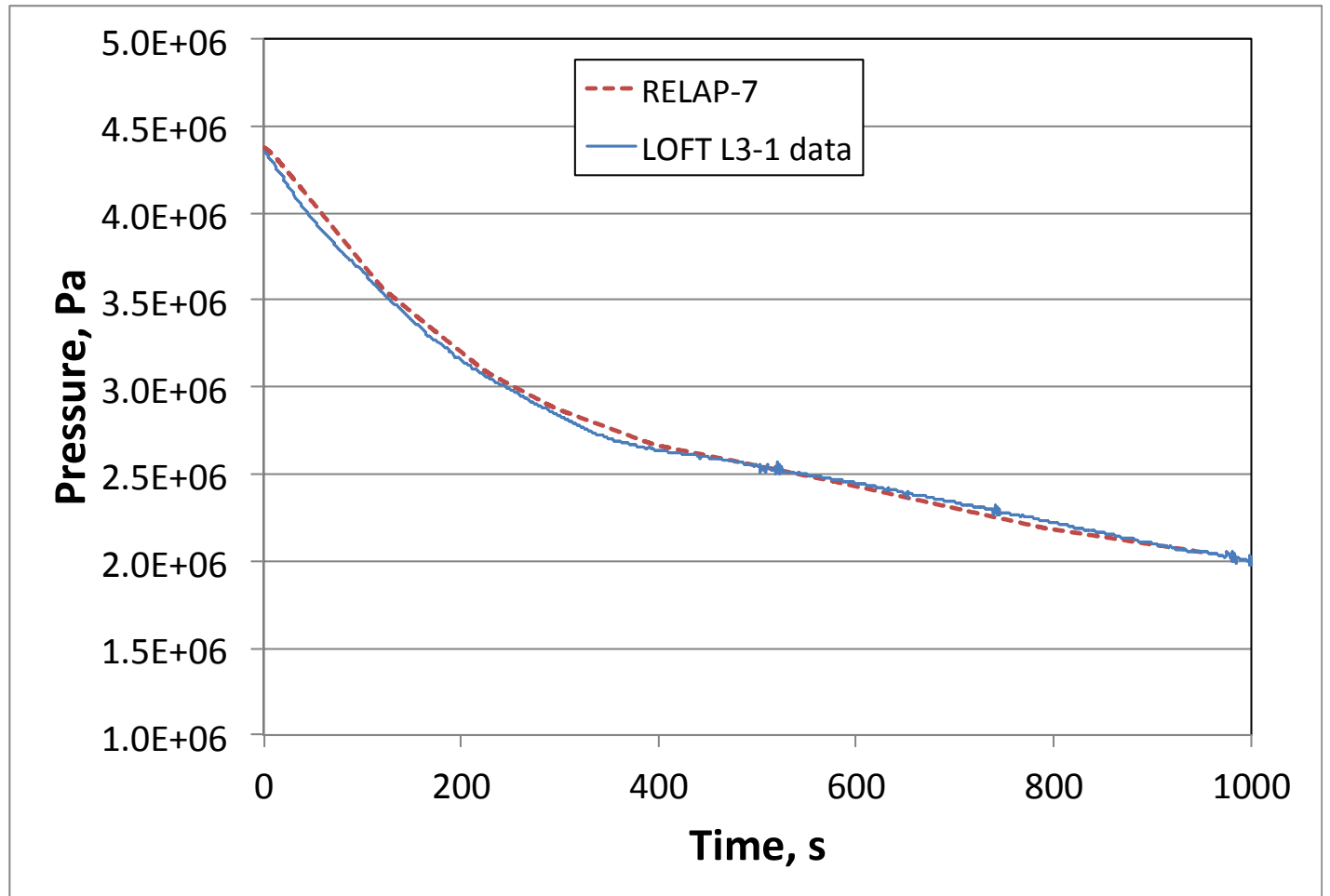

Figure 4. Calculated RELAP-7 accumulator gas pressure versus LOFT L3-1 experimental data.

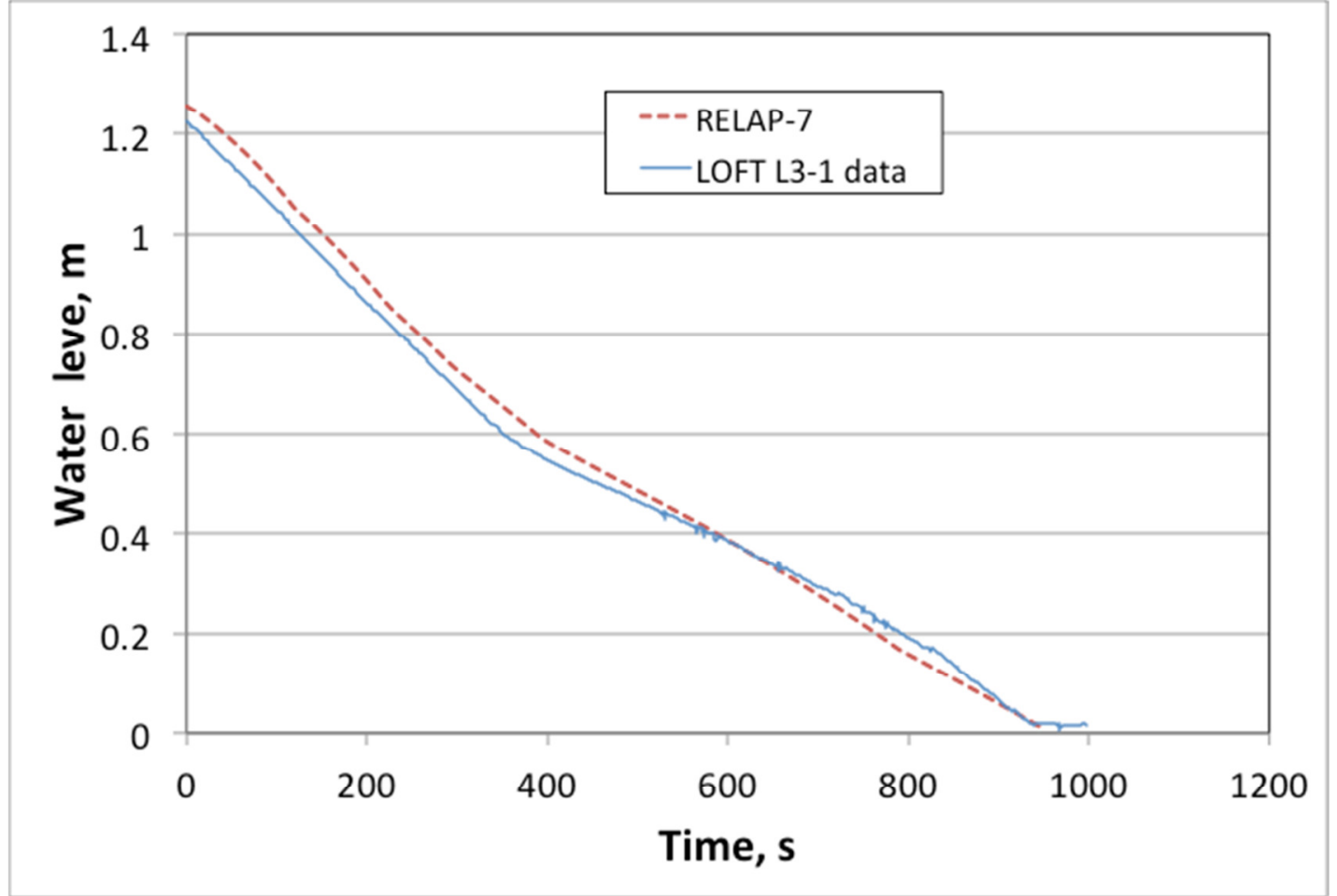

Figure 5. Calculated RELAP-7 accumulator water level versus LOFT L3-1 experimental data. 


\subsection{Numerical Verification of RELAP-7}

Numerical verification, by proving the order of accuracy, is an essential part of modern verification and validation $(\mathrm{V} \& \mathrm{~V})$ process. $\mathrm{V} \& \mathrm{~V}$ plays a very important role in quantifying uncertainties and realizing high-fidelity simulations in engineering system analysis. Numerical verification can be performed by demonstrating the convergence rates of the time integration scheme and spatial discretizing method, which are commonly used in the CFD method development community. For example, if the time scheme is 2 nd order in theory and the numerical errors do drop in 2 nd order when the time step is halved, the time convergence rate is confirmed. The criterion for numerical verification is that the numerical convergence rate is equal or close to the theoretical convergence order. Strict numerical verification process is a very effective way to eliminate code bugs, which cause lower order errors. For example, boundary condition errors or coupling errors often cause 0th or 1st order errors. By confirming 2 nd order convergences in both time and space, the number of code bugs can be dramatically reduced.

The RELAP-7 code has the capacity to realize 2nd order numerical accuracies in both time and space. Time integration options with different order of accuracies are available for users to choose, for example, BDF2 (backward differentiation formula in 2nd order) and Backward Euler (BE, 1st order).

This section presents the numerical verification work for a single phase natural circulation loop. Strict numerical verification in both time and space for a system level simulation is rare in literature. A system level simulation model is composed of multiple 1-D domains connected by 0-D components. Even each single domain model can be proven to be 2 nd order accurate in space, errors in 0-D components can degrade the convergence order. Therefore, system level numerical verification is a necessary step of the $\mathrm{V} \& \mathrm{~V}$ process in new code development to identify these potential errors. RELAP-7 is a fully implicit code. The time step in RELAP-7 is not limited by the material Courant number. However, the numerical error may become too large relative to the uncertainties from physical models for large time steps. Similar argument is true for space discretization. Therefore, it is a good practice to perform numerical verification to show what sizes of time step and grid are proper for different types of problems.

The model used in this work, as shown in Fig. 6, is an imaginary scaled experiment. The typical PWR core channel $(2 \times 2$ fuel rods $)$ is used for the heating section. The cooler is a tube-shell type counter-current heat exchanger (HX) with primary coolant inside the pipe. The pipes are also arranged in a $2 \times 2$ square shape. 


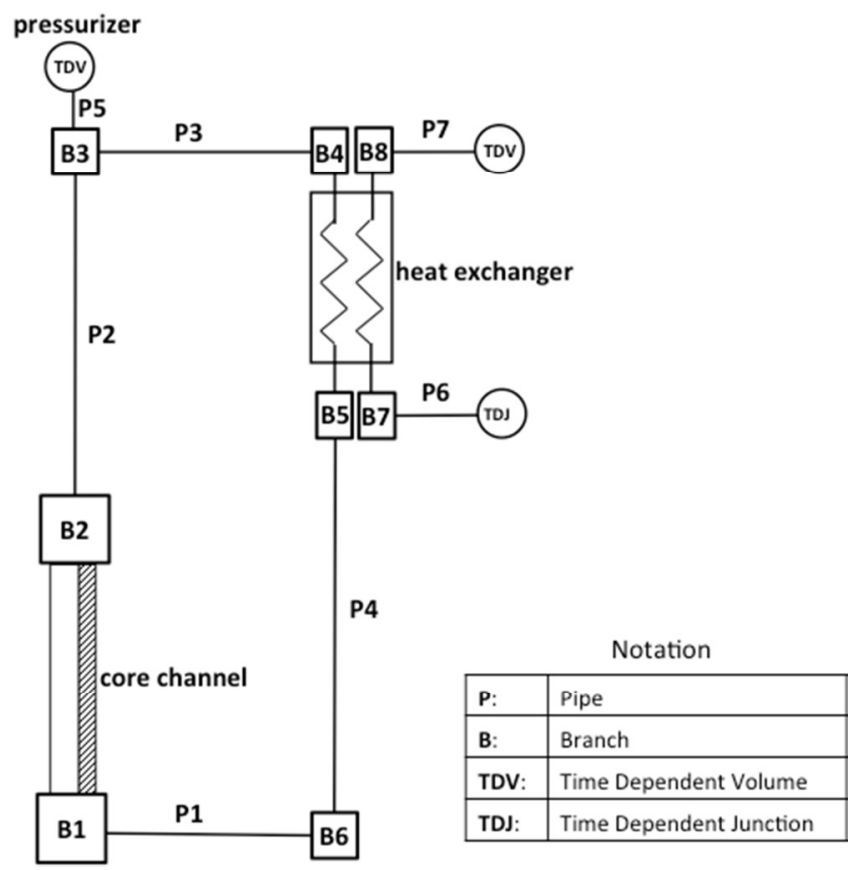

Figure 6. Schematic of the natural circulation loop problem.

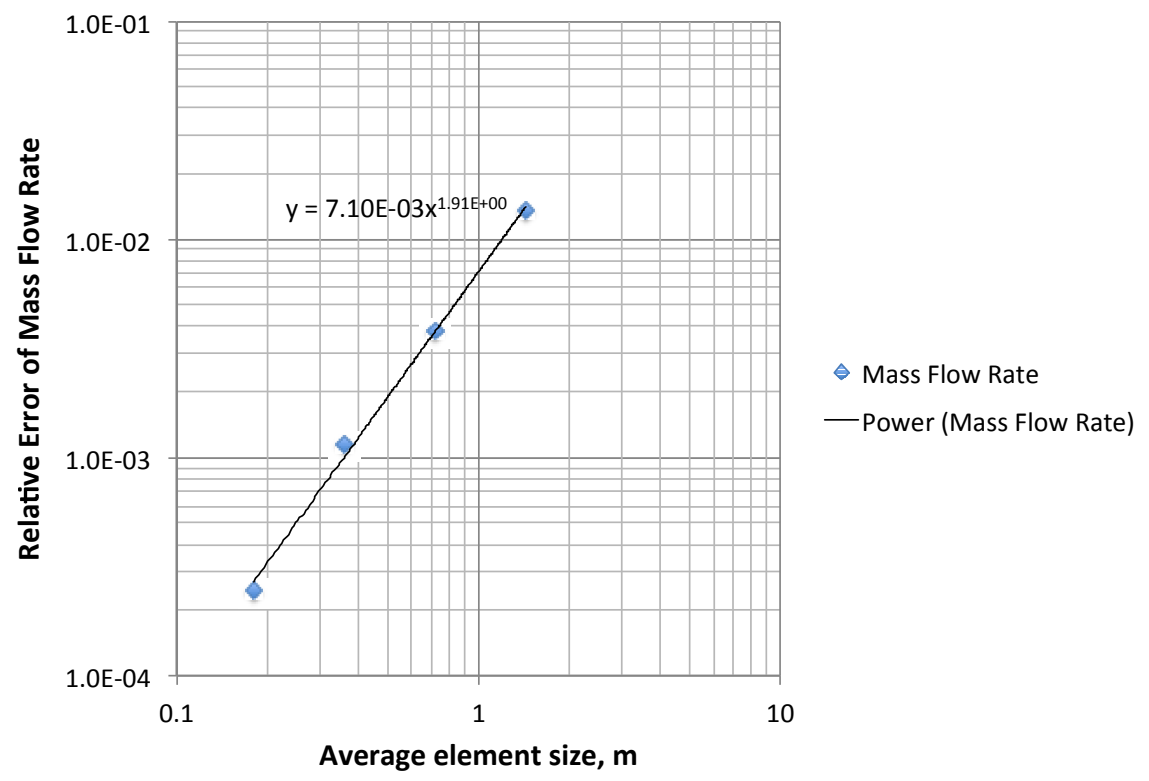

Figure 7. Spatial convergence rate for mass flow rate error.

Fig. 7 shows the spatial convergence study. A small time step of $0.025 \mathrm{~s}$ is used for all the cases to minimize the time integration error. The convergence rate of 1.91 is very close to the theory value of 2 ; therefore, we can claim that the 2nd order accuracy in space is obtained for this natural circulation loop problem. Note that the largest element size $-1.44 \mathrm{~m}$ results in over $1 \%$ of relative mass flow rate error. This level of error is close to the measurement uncertainty range. Therefore, this element size should be taken as the upper limit for any meaningful simulations so that numerical errors are still small enough 
comparing to physical uncertainties. $2^{\text {nd }}$ order convergence rate has also been demonstrated for the test case in the asymptotic region. Proper choice of time steps has been recommended. More detailed description of the numerical verification studies can be found in Ref. [11].

Numerical verification is an essential part of modern verification and validation process for reactor safety system code development. Strict numerical verification works for a single phase natural circulation loop simulation with the RELAP-7 code have been performed. Second order convergence rates for both time and space are confirmed with selected figure of merits. For a fully implicit code like RELAP-7, although the time step and grid size are not limited by stability requirement, the numerical errors may limit their sizes. Numerical verification can tell users the proper sizes of time step and grid for different types of problems.

\subsection{Multi-Physics Coupling}

Efforts have been under going to couple RELAP-7 with other MOOSE based applications such as neutronics code Rattlesnake and fuel performance code BISON. The coupling of RELAP-7 with Rattlesnake and BISON are done in a split operator approach. Each system has to solve its physics on a separate mesh and, for RELAP-7 and BISON, only a subset of the full problem domain. Rattlesnake solves the neutronics over the whole domain which includes the fuel, cladding, gaps, water, and top and bottom rod holders. Here BISON is applied to the fuel and cladding, and RELAP-7 is applied to the flow of the circular outer water channel. The mesh on the Rattlesnake side can either be 3D (for low order transport) or 2D (for diffusion). BISON has a matching ring structure mesh for the fuel so both the power density and local burnup are copied accurately from Rattlesnake.

Since a split operator approach is applied, Rattlesnake calculates a power density, burn-up distribution and fast flux based on the current water density and fuel temperature. These are then mapped to the BISON mesh for a fuels performance solve. BISON calculates the fuel temperature and cladding surface temperature based upon the current power density and bulk fluid temperature. RELAP-7 then calculates the fluid temperature, water density fraction and water phase velocity based upon the cladding surface temperature. The fuel temperature and the fluid density are then passed back to RattleSnake for another neutronics solve.

Rattlesnake takes depletion time steps. At each step Rattlesnake calls BISON to do a fuels performance solve with the latest power density and burnup distribution mapped from the 3D (or 2D) Rattlesnake mesh to the BISON mesh. BISON can take smaller time steps or sub-cycle between each Rattlesnake depletion time step and calls RELAP-7 at each fuel performance solve. RELAP-7 can subcycle between each fuel performance solve.

A single fuel pin was modeled based on the dimensions of a Westinghouse $17 \times 17$ fuel rod. To eliminate azimuthal effects, the water channel was approximated as a cylinder with a reflective boundary condition applied on the outer boundary in the Rattlesnake solution, with and boundary conditions at the top and bottom of the rod end-fittings set to vacuum. Rattlesnake macroscopic cross sections were obtained from a DRAGON5 single pin depletion calculation. BISON used an axi-symmetric mesh consisting of both the fuel element and the surrounding cladding. The fuel rod dimensions are given in Table 1.

The simulation consisted of a depletion period of 1343 days, roughly equal to three full operating cycles, followed by a station blackout (SBO) event. The fuel rod was depleted for 1343 days for a near constant total power loading of $65.81 \mathrm{~kW}$. After 1343 days the fission power was reduced to zero (simulating a reactor shut-down). Decay heat calculations provided the time-varying energy source after 
this time. RELAP-7 simulated a pump shut down at the time of the event by reducing both the vapor and liquid densities and decreasing the heat transfer coefficient.

Table 1. Dimensions of single Westinghouse 17x17 Fuel Pin

\begin{tabular}{|l|l|}
\hline Parameter & Value \\
\hline Fuel Rod Height & $426.72 \mathrm{~cm}$ \\
\hline Active Fuel Height & $389.61392 \mathrm{~cm}$ \\
\hline Fuel Pellet Radius & $0.4025 \mathrm{~cm}$ \\
\hline Gas Gap Thickness & $0.0085 \mathrm{~cm}$ \\
\hline Upper Gas Plenum Height & $18.55304 \mathrm{~cm}$ \\
\hline Lower Gas Plenum Height & $13.91478 \mathrm{~cm}$ \\
\hline Clad Thickness & $0.064 \mathrm{~cm}$ \\
\hline Upper and Lower End Fitting Heights & $2.31913 \mathrm{~cm}$ \\
\hline Pin Pitch & $1.42063 \mathrm{~cm}$ \\
\hline Effective Moderator Radius & $0.710315 \mathrm{~cm}$ \\
\hline Fuel Composition & $4.15 \mathrm{wt} \% \mathrm{UO}$ \\
\hline
\end{tabular}

Figure 8 shows the temperature and power profiles at the time of the event based on the evolution of isotopic distributions from depletion calculations performed using Rattlesnake with a two-group diffusion model during the pre-trip phase. The temperature distribution (left) and the power density distribution (right) for the fuel element before the accident are given (the left side of each figure is the fuel centerline). For the power density a thin layer of plutonium had built up along the edge of the fuel rod causing the large jump in power distribution at the fuel rod edge.

Figure 9 shows the liquid vapor fractions at 1343.0 days and 68.45 seconds after the pumps have shut off. Before the station blackout the liquid fraction is near or greater than 0.99 and the vapor fraction is less than 0.01. After the station blackout the results show a dramatic change with the largest amount of liquid at the bottom of the fuel rod and the largest amount of vapor at the top of the fuel rod, as a result of loss of flow following the SBO. 

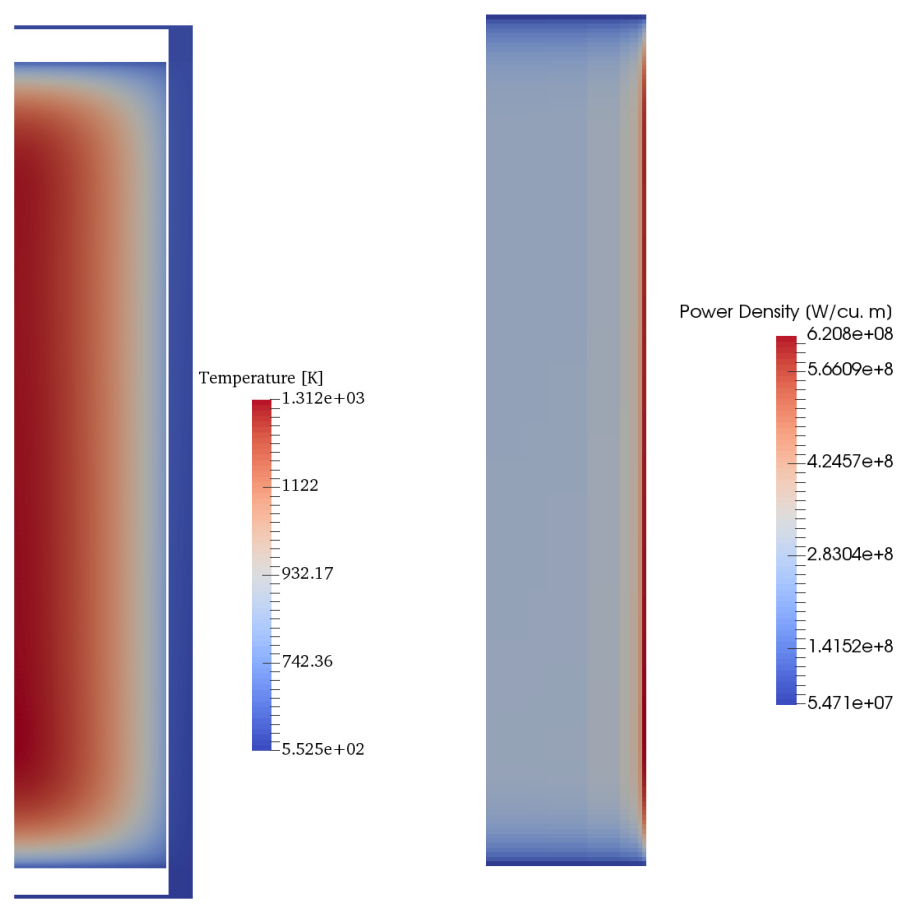

Figure 8. Plot of fuel rod radial average temperature $[\mathrm{K}]$ before station blackout (left figure) and plot of fuel power density [Watts/cu m] before station blackout (right figure).

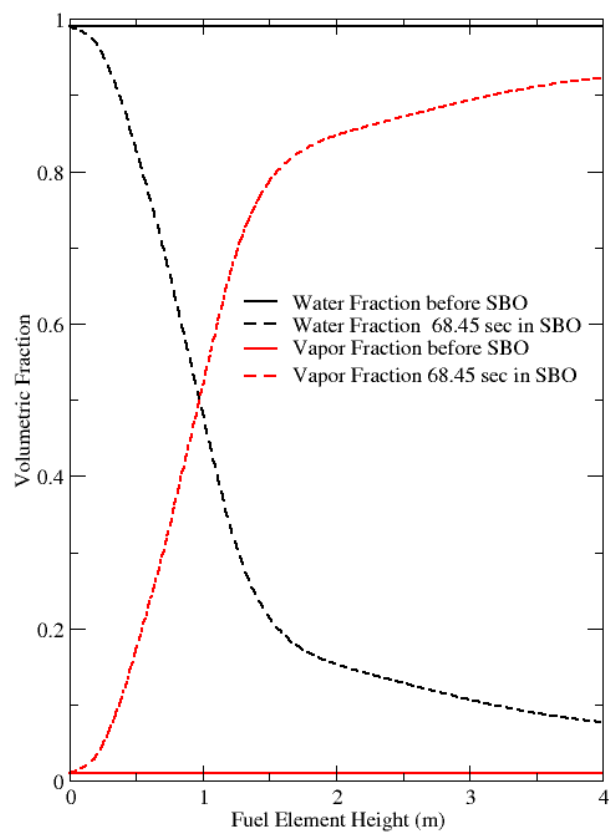

Figure 9. Plot of liquid-vapor fraction vs. fuel rod height both before station blackout (SBO) and 68.45 seconds after station blackout. 
The coupling of Rattlesnake, BISON, and RELAP-7 has been demonstrated for the modeling of single pin during depletion followed by a station blackout transient in which flow slows then stops as pumps coast down (this assumes no backup power). The coupling between codes allows direct coupling between neutronic, fuel performance, and thermal-hydraulic solvers, illustrating the capability of MOOSE to transfer different data across different aligned domains to resolve an inherently multi-physics problem. The results presented here are a sampling of the multi-physics results that can be obtained from such a simulation. Note that the results shown here do not show the evolution of the structure and dynamic behavior of the fuel pin itself (swelling, creep-down, etc.) although that information was available to RELAP-7.

\section{SUMMARY}

During Fiscal Year 2015, the RELAP-7 code has been further improved with expanded capability to support boiling water reactor and pressurized water reactor nuclear power plants analysis. The accumulator model has been developed. Numerical verification work has also been performed to verify that the RELAP-7 code indeed can achieve second order accuracy in both time and space for single phase models at the system level. The code has also been coupled with other MOOSE based applications such as neutronics code RattleSnake and fuel performance code BISON to perform multi-physics analysis. 


\section{REFERENCES}

1. RELAP-7 Level 2 Milestone Report: Demonstration of a Steady State Single Phase PWR Simulation with RELAP-7, INL/EXT-12-25924, Idaho National Laboratory, May 2012.

2. RELAP-7: Demonstrating Seven-Equation, Two-Phase Flow Simulation in a Single Pipe, Two Phase Reactor Core and Steam Separator/Dryer, INL/EXT-13-28750, Idaho National Laboratory, April 2013.

3. RELAP-7 Simulation Resolving an SBO Scenario on a Simplified Geometry of a BWR, INL/EXT-13-29887, Idaho National Laboratory, August 2013.

4. RELAP-7 Theory Manual, INL/EXT-14-31366, Idaho National Laboratory, February 2014.

5. INL, RELAP5-3D Code Manual Volume I: Code Structure, System Models and Solution Methods, INEEL-EXT-98-00834, Rev. 4, June, 2012.

6. Carlson, K. E., et al. Mechanistic accumulator model for light water reactor transient analysis. No. CONF-810804-21. Idaho National Engineering Lab., Idaho Falls (USA), 1981.

7. Bayless, Paul D., J. Bruce Marlow, and Rahland H. Averill. Experiment data report for LOFT nuclear small break experiment L3-1. No. NUREG/CR-1145; EGG-2007. Idaho National Engineering Lab., Idaho Falls (USA), 1980.

8. Shiraishi, Tadashi. "Design of the advanced accumulator for the pressurized water reactor." Nuclear Engineering and Design, Vol. 241, No. 9, pg. 3910-3924, 2011.

9. Berry, R. A., J. W. Peterson, H. Zhang, R. C. Martineau, H. Zhao, L. Zou, and D. Andrs. "Relap7 theory manual." Idaho National Laboratory, Living Tech. Rep. INL/EXT-14-31366, 2015.

10. Bayless, P. D. "RELAP5-3D Code Manual Volume III: Developmental Assessment." INEELEXT-98-00834, Idaho National Laboratory, December 2011.

11. H. Zhao, L. Zou, H. Zhang, R. Martineau, "Numerical verification of RELAP-7 model for a single phase natural circulation loop," ANS Transaction Vol. 112, 2015. 